Review

\title{
Altered Gut Microbiome in Autism Spectrum Disorder: Potential Mechanism and Impl- ications for Clinical Intervention
}

\author{
Kuokuo Li ${ }^{1}$, Zhengmao $\mathrm{Hu}^{1}$, Jianjun $\mathrm{Ou}{ }^{2}$, Kun Xia 1,*
}

1 Center for Medical Genetics and School of Life Sciences, Central South University, Changsha, Hunan, China

2 Department of Psychiatry and Mental Health Institute of the Second Xiangya Hospital, Central South University, Changsha, Hunan, China

Received July 18, 2018; Accepted January 2, 2019

\begin{abstract}
Autism spectrum disorder is a heterogeneous neurodevelopmental disorder with an increased prevalence around the world over the past two decades. Remarkably, a large number of individuals with ASD have gastrointestinal disorders. Recent studies demonstrate that the endogenous gut microbiota has a close relationship with ASD according to the analyses of human host intestinal microbial composition and animal model studies. Here, we review the reports of microbial dysbiosis in ASD, and then discuss the recent evidence of biological interactions among microbiota, metabolism, immunity, neurodevelopment, and behaviors. We also describe the role of the gut microbiome in the link between ASD and environmental risk factors. Finally, we suggest adjuvant treatments to consider in attempts to correct autistic behaviors.
\end{abstract}

\section{KEYWORDS}

Gut microbiome; autism spectrum disorder; clinical interventions

\section{INTRODUCTION}

Autism spectrum disorder (ASD) is a common neurodevelopmental disorder characterized by persistent deficits in social communication as well as unusually restricted and repetitive patterns of behavior or interests. Partly due to the changes in the diagnostic criteria, the prevalence of ASD has been reported from 0.60 to $2.64 \%$ [1-3]. The number of ASD cases was estimated at 62.6 million around the world in 2015, and the costs of the care for ASD children impose an enormous burden on families $[4,5]$. In addition, individuals with ASD often experience co-morbid disorders including irritability, aggression, sleeping problems, developmental delay and epilepsy [6-8], which may cause additional medical expenses.

While population-based family studies estimate the heritability approximate $50-90 \%[9,10]$, only a few common variants that contribute to the heritability have been associated with ASD. Previous large-scale genetic studies have identified a number of rare variants such as copy number of variants and single point mutations [11], and the shared environmental influence was 30\% [10]. ASD children often have gastrointestinal problems such as abdominal pain, diarrhea, and constipation [12-14], which are associated with the microbiome, in particular, evidence of Sutterella species have been found in the pati-

* Correspondence: Likuokuo@sklmg.edu.cn or xiakun@sklmg.edu.cn ents diagnosed with ASD but not in the control children with GI symptoms [15].

In this paper, we provide an overview of recent evidence about the interrelation among the gut microbiome, metabolism, immunology, and neurobiology. We review the epidemiological studies of gastrointestinal diseases and the composition of the gut microbiome in individuals with ASD, and then discuss gut-immune function, neurodevelopment, metabolism, and other environmental factors. Finally, we review the existing evidence at a molecular level that might suggest some possible therapeutic interventions.

\section{GASTROINTESTINAL DISTURBANCES AND GUT MIC- ROBIOTA}

While the prevalence of digestive problems in ASD individuals has been reported varying at $23-70 \%$, there is evidence that individuals with ASD have more likelihood of having gastrointestinal disorders [12]. A study found a strong correlation between gastrointestinal symptoms with autism severity [16], and altered gut microbiota has been found in children with ASD.

Microorganisms in the gut are essential for the host and play a crucial role in digestion $[17,18]$. Nondigestible nutrients such as polysaccharides and cellulose can be fermented by microbiota in the intestine to produce energy 
and short chain fatty acids [18]. The short chain fatty acids, including butyrate produced by a single bacteria strains, Clostridium tyrobutyricum (CBut), acetate and propionate produced by Bacteroides thetaiotaomicron (BEta), can influence the expression of the tight-junction proteins (ZO-1, occludin, claudin-5) which are related to blood-brain barrier permeability and thus may have a secondary impact on the function of the brain [19].

Meanwhile, individuals with ASD have a different composition of microbiota in the gut compared with the neurotypical-developed children (NTD) [20]. Sutterella were found in more than $50 \%$ of individuals with both ASD and intestinal dysfunction, but not in the NTD children with pure dysfunction of the gut $[21,22]$; and Kang reported lower levels of Prevotella, Coprococcus, and unclassified Veillonellaceae in the gut bacterial populations in children with ASD [23]. It has been indicated that changes in a few microbial species may lead to behavioral problems but the mechanism is not defined.

\section{METABOLIC DISTURBANCE AND GUT MICROBIOME}

The metabolic disturbance has been observed in individuals with ASD. Compared to their unaffected siblings and age-matched healthy controls, children with ASD children tend to have a distinct profile of metabolic phenotyping in urine [24]. Through a metabolomic analysis, docosahexaenoic acid (DHA) and sphingosine 1-phosphate (S1P) in serum have been found to be lower in individuals with autism [25] and an elevated level of p-cresol in urine has been identified and replicated in an independent study [26]. In the human gastrointestinal tract, symbiotic bacteria play an indispensable role in degrading nondigestible carbohydrates.

Animal studies suggest that those metabolic changes are likely due to an imbalance of the gut microbiome. Germfree mice show a significant difference in metabolites in luminal contents of the colon compared with ex-germ free mice which were with a gavage of feces from specific pathogen-free mice [27], indicating that the microbiota may profoundly influence the colonic luminal metabolome. The metabolomic analysis also suggested that gut microflora have significant effects on mammalian blood metabolites [28].

When rats were treated with maternal high-fat diet (MHFD) for several weeks, the level of acetate dramatically increased due to the gut microbiota-food interaction. Acetate may increase glucose-stimulated insulin secretion (GSIS) across the activated parasympathetic nervous system [29]. This positive feedback may lead to the development of obesity as a critical element of the metabolic syndrome. Another study in mice shows that a high-fat diet altered the composition of gut microbiota including Bifidobacterium, which plays a functional role in barrier-protection [30]. Further, in contrast with mice with a gavage of heatkilled bacteria, mice with a gavage of Akkermansia muciniphila showed maintenance of the intestinal barrier and a reversal of high-fat-diet-induced metabolic disorders, including fat-mass gain and insulin resistance [31, 32].
Studies have shown that the gut microbiota modulates ASD-related behaviors and affect the levels of specific metabolites. Gastrointestinal barrier defect and alteration of microbiota have been noted in maternal immune activation (MIA) mouse model associated with ASD [33]. MIA offspring treated with the human commensal Bacteroides fragilis had a significant improvement in gut permeability, microbial composition, and ASD-related behaviors. This treatment also modulates the levels of several specific metabolites, suggesting that gut bacterial effect on the host metabolome affect behaviors. These findings support a gut-microbiome-brain connection in a mouse model of ASD.

\section{IMMUNE DYSREGULATION AND GUT MICROBIOME}

Immune dysregulation including maternal inflammation or infection may increase the vulnerability of neurodevelopment, such as ASD [34-38]. A study of brain tissues and cerebrospinal fluid (CSF) have shown an activation of microglia and astroglia or a marked increase in a small cytokine monocyte chemoattractant protein 1 (MCP1) in individuals with ASD [39]. A meta-analysis of 19 cytokines in plasma and serum from 17 studies shows that individuals with ASD have a marked elevation of prionflammatory cytokines, including interleukin (IL)-1, IL-6, IL-8, interferon (IFN)- $\gamma$, eotaxin, MCP1 in blood compared with healthy controls [40]. However, consistent data are still lacking for other cytokines, likely due to the difference in the methodology, etiological variability and population heterogeneity [41-43].

The immune system and gut-resident microbes have a pronounced interaction [44]. In an animal model, MIA causes an ASD-like phenotype and the maternal inflammation during critical periods of the embryonic development leads to an alteration of the immune system and further disturbs the fetal environment, which may cause aberrant behaviors in offspring [45]. MIA male mice offspring show a lower rate of ultrasonic vocalizations, fewer harmonic, and more complex voice, which may continue into adulthood. Additionally, MIA offspring display increased repetitive or stereotyped behaviors, a mouse version of the core symptoms of autism $[33,45,46]$. The target region of MIA was located in the primary somatosensory cortex (S1DZ) [47] where there was an increase in neural activities that project to the temporal association cortex (TeA) or striatum in this cortical region, which can in turn result in impaired sociability. Moreover, the inhibition of neural activity is sufficient to suppress the abnormal behaviors [47].

Despite the fact that immune activation contributes to abnormal behaviors, it is not clear how microbes participate in the induction of immune activation. In the germ-free mice, the introduction of gram-positive gutresiding segmented filamentous bacteria (SFB) can cause an autoimmune disorder [48]. SFB increase the number of T helper 17 ( $\mathrm{T}_{\mathrm{H}} 17$ ) cells, which differentiate from CD4+T cells induced by the collaboration of TGF-b and IL- 6 and secrete IL-17 in promoting inflammatory responses. Maternal colonization of SFB together with 
injection of poly (I:C) can stimulate the activity of $\mathrm{T}_{\mathrm{H}} 17$ cells and lead to abnormal behaviors in offspring [49]. However, mice injected with poly(I:C) alone show a significant increase in TNF $\alpha$ and IFN- $\beta$ compared with endotoxin-free phosphate-buffered saline (PBS)-injected mice, but not exhibit the change in the behaviors of offspring. Treatment of pregnant mice with vancomycin reducing SFB and the abnormal behaviors of offspring can be rescued [49]. In contrast to SFB, some other microbes are involved in suppressing the immune response in the host. Mucosal colonization of Bacteroides fragilis could suppress $\mathrm{T}_{\mathrm{H}} 17$ response in germ-free mice [50]. The underlying mechanism may be that the polysaccharide $\mathrm{A}$ on Bactericides fragilis promotes immunol-ogic tolerance through increasing the proportion of regulatory $\mathrm{T}$ cells by action at the Toll-like receptor $2[50,51]$.

Another potential bacterial modulator of MIA is the lipopolysaccharide (LPS) endotoxin located on the surface of gram-negative bacteria. LPS can bind the Toll-like receptor receptors, which that trigger an immune response. Maternal inflammation in mice triggered by LPS (E. coli serotype 0111:B4) can cause a proliferation of neural stem and progenitor cells in offspring, which also exhibited autism-associated behaviors including reduced ultrasonic vocalizations [52-54]. A study showed that offspring of rats with maternal immune activation by LPS had an alteration of specific gene expression profiles of interneuron migration and oxidative stress without a triggering a fetal immune response and exhibited reduced social and exploratory behaviors [55].

\section{GUT MICROBIOME AND NEURODEVELOPMENT}

The microbial composition and function in the intestine affect the development of nerve cells from the embryo to adulthood. These effects include the differentiation of neural stem cells, migration, and projection of immature neurons to their destinations, the growth of axons and dendrites, and the formation of synapses. While germfree mice exhibited an increase in adult neurogenesis in the dorsal hippocampus, which plays a role in spatial learning and memory, the recolonization of microbiota in germ-free adult mice cannot change this tendency, suggesting a critical part of microbiota in early developpment life. This is consistent with the past demonstration that stress or long-term antibiotic treatment may potentially inhibit neurogenesis in the hippocampus [56].

Microglia are tissue macrophage cells located in the brain that participate in immune responses including removal of dead cells and pathogens. Several studies found that marked activation and augmented number of microglia in different regions of the brain are pathophysiologic characteristics of ASD $[39,57,58]$. The complexities of host microbiota can contribute to maturation and function of microglia. Germ-free mice exhibited global defects in microglia with altered cell proportions and an immature phenotype, which show impaired innate immune responses to LPS. The full repertoire of microbes or SCFA is necessary and sufficient to restore impairment of microglia stability [59].
Administration of antibiotics to the pregnant mice not only influence gut microbiome composition but also affect the behavior of the offspring in locomotor activity and anxiety. It has been shown that the behaviors of the offspring from antibiotic-treatment pregnant-mice can be rescued at week 4 when normal pregnant mice fostered them from the post-natal day one [60]. Another study found that female rats exposed to a diet containing $1 \%$ succinyl sulfa thiazole, a non-absorbable antibiotic, during periconceptional period, can alter the offspring behaviors without maternal infection, also likely due to the alteration of maternal gut microbiota [61].

\section{GUT MICROBIOME LINKS BETWEEN ASD AND ENVI- RONMENTAL RISK FACTORS}

Neurons are highly sensitive and vulnerable to environmental factors such as maternal stress in early development in humans, especially in the first three years. The method of delivery, breastfeeding, maternal separation and infection all may have an impact. The mode of obstetrical delivery has a significant influence on the composition of the intestinal microbiota at the very beginning of human life $[62,63]$. Epidemiological studies report that cesarean section (C-section) delivery is associated with the non-communicable chronic diseases including immune and metabolic disorders [64]. Children born by $\mathrm{C}$-section including elective and emergency Csection are more likely to have ASD, although this tendency does not appears in sibling controls $[65,66]$. Children delivered through C-section show a different pattern of gut microbiome compared to infants born via vaginal delivery. This difference seen in C-section infants can be restored to that seen in vaginally delivered infants by exposure to maternal vaginal fluids [67].

Maternal stress is another environmental factor that may affect major physiological systems including neurodevelopmental disorders. Maternal stress increases the proinflammatory state of the fetal central nervous system, and such neuroimmune inflammation has been implicated in ASD [68]. The microbiome of the maternal vagina can be disturbed by the early-life stress and in turn influence the gut microbiome of offspring. For example, the decrease of Lactobacillus in the maternal vagina of the mouse model may lead to a reduction in the transmission of this bacterium to offspring, which influence the offspring microbiota composition and metabolic processes that are essential for normal neurodevelopment [69]. In addition, prenatal stress induces impairment of novel object recognition memory in a rat model, which shows a significantly lower memory index measured by novel object recognition test (NORT) [70].

Maternal infection with different types of agents (bacterial, viral, parasitic, and fungal) and site of infection (genitourinary infections and skin infections) during pregnancy is another risk factor that can increase the prevalence of abnormal behaviors associated with autism [71, 72]. Maternal infection affects the maternal immune responses and the fetal neurodevelopmental environment at a critical time. In utero exposure to valproic acid (VPA), a 
drug used to treat epilepsy and bipolar disorder, causes a change in the composition of gut microbiota and further influences metabolism in a murine model of ASD [73].

Maternal exposure to pesticides and certain fungicides such as pyraclostrobin, trifloxystrobin, famoxadone and fenamidone in the environment or the food, is associated with the neurodevelopmental disorders including ASD $[74,75]$. All these chemicals produce transcriptional changes in vitro that are similar to those observed in brain samples from individuals with autism including stimulation of free radical production and disruption of microtubules in neurons. These effects can be reduced by pretreating with a microtubule stabilizer, an antioxidant, or with sulforaphane [76].

\section{THE DIRECTION OF POTENTIAL INTERVENTIONS}

So far, several potential mechanisms including immune, metabolic and neurological pathways have been implicated by the use of animal and cellular models, and each of these pathways can be considered as potential therapeutic targets for one or more phenotypes of ASD. First, psychotropic drugs including risperidone and aripiprazole are often used to improve behavioral symptoms of ASD. The atypical antipsychotic risperidone was the first drug approved by the FDA for treating repetitive behavior and hyperactivity, and it acts via modulation of the 5-HT and dopamine neuronal systems, which are related to ASD [77-81]. Second, sulforaphane or broccoli extracts can reduce free radical production and protect microtubules in neurons by inducing expression of $\mathrm{Nrf} 2$, which is a transcription factor that regulates the expression of antioxidant proteins and protect cells against oxidative damage $[74,82,83]$. ASD children taking oral sulforaphane for 18 weeks had improvement of phenotypes including social interaction and communication after discontinueing treatment about four weeks [76]. Third, oxytocin treatment or activating oxytocin neurons can also restore the ASD-like social behaviors in Cntnap2 knockout mice, which shows a reduced number of oxytocin neurons [84]. Detailed discussions of the mechanism relating oxytocin and neuromodulation in ASD as well as potential medical treatments have been presented in the literature in the past $[85,86]$.

Further, evidence shows the relationship between the intestinal microbiome and the function of the nervous system. It has become plausible to consider using commensal probiotics to treat neurodevelopment diseases such as ASD. For example, MIA mice offspring treated with a single organism, Bacteroides fragilis, show improved ASDrelated defects in the core symptoms of communicative, stereotypic, anxiety-like and sensorimotor behaviors [33, 45]. In another study in mice, Lactobacillus reuterias, a single probiotic and a commensal strain, corrected the social deficits in the MHFD offspring by inducing incresed oxytocin [87].

Finally, fecal microbiota transplantation (FMT) has already been used to alleviate intestinal diseases such as irritable bowel syndrome (IBS) and inflammatory bowel disease (IBD), presumably by correcting the composition of the gut microbiota [88-90]. A recent report indicates that Microbiota Transfer Therapy (MTT) and then an extended fecal microbiota transplant (FMT) can improve autism symptoms and alter the gut ecosystem [91]. In this open-label study, autistic individuals with moderate to severe gastrointestinal problems were treated with antibiotics for two weeks and then used a dose of standardized human gut microbiota for 7-8 weeks. ASD-related symptoms showed a significant improvement.

Although the prospects are promising, potential negative aspects of treatment on the subject must be considered. Children treated with risperidone do not improve core behaviors associated with autism, and improved symptoms will return to the original state when the drug is discontinued. Moreover, children showed a significant gain in weight due to an increased daily intake of food, especially carbohydrates that may have implications for risk of insulin resistance and metabolic syndrome [92]. Microbiota transplantation may also disturb the balance of the intestinal microbial composition. Individuals with recurrent Clostridium difficile infection who received FMT had adverse events such as diarrhea, abdominal discomfort, and even one death occurred because of aspiration during sedation for FMT administered via colonoscopy in the treatment of Clostridium difficile infection [93-96]. Whether diverse microbiota does benefit or harm to the homeostasis of the intestine are still unknown at present, and it is also not yet understood what microbes play vital roles in the healthy functioning of the gut. Therefore, indepth characterization of defined communities or even various individual microbial species that may ameliorate ASD symptoms should be a focus in the future.

\section{CONCLUSION}

In summary, environmental risk factors contribute to the development of ASD and the role of the gut microbi-ome in host homeostasis is now well established. The gut microbiome influences metabolism, immunity, and neurophysiology and these converge to influence development processes in the brain and following behaviors (Figure 1). We have reviewed recent evidence for neurodevelopment and behavior changes in both animal models and humans as influenced by gut microbiome status for ASD-associated behaviors. However, the possible mechanism depends upon exposure to specific microbes, beneficial or pathogenic, induction of certain phenotypes in the immune system, the metabolic system, the central nervous system, or the enteric nervous system.

\section{CONFLICTS OF INTEREST}

The authors declare that there is no conflict of interest regarding the publication of this paper.

\section{ACKNOWLEDGEMENTS}

This work was supported by the National Science Foundation of China (NSFC) (81330027, 81525007). 


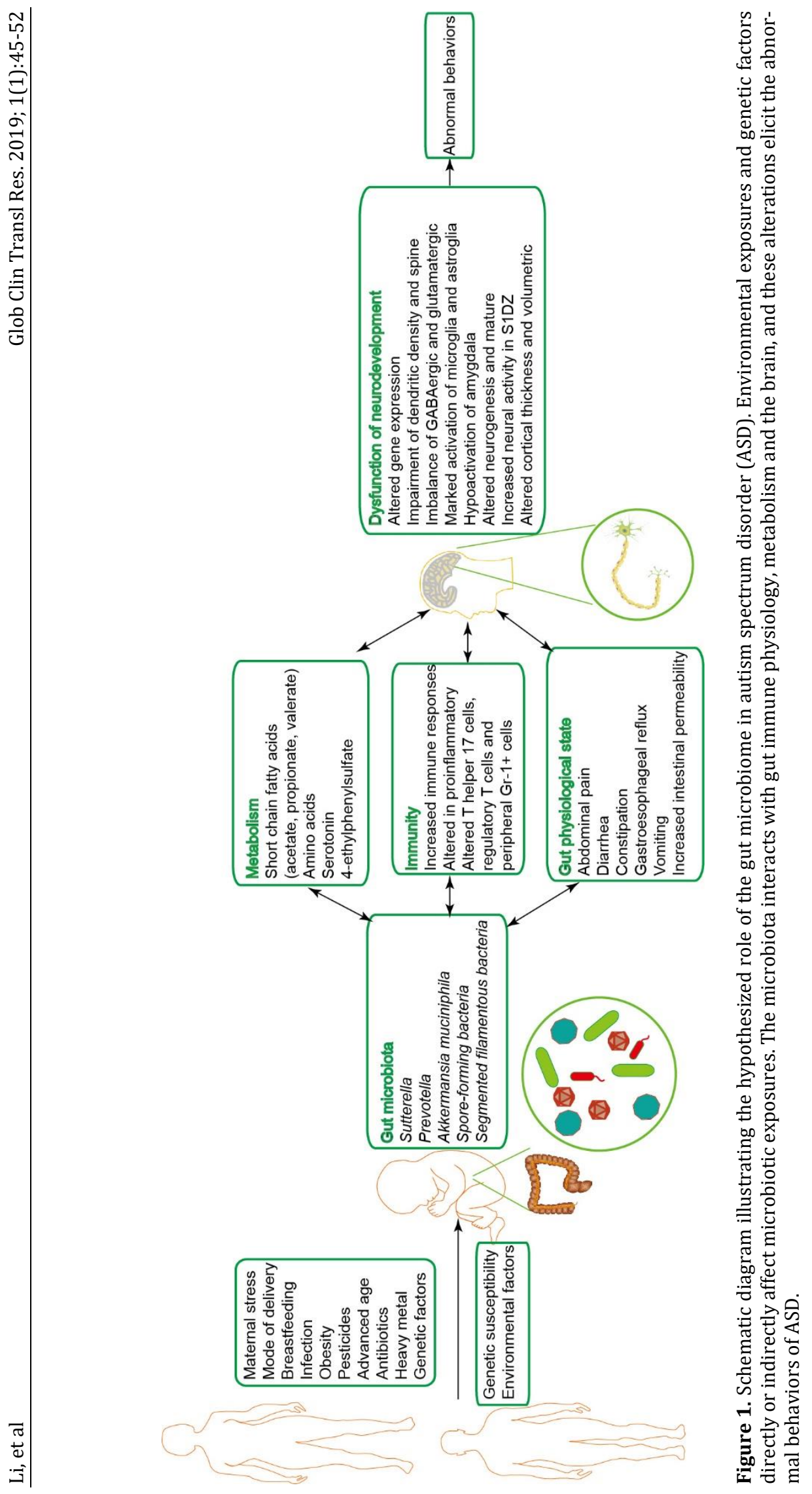




\section{REFERENCES}

1. Autism and Developmental Disabilities Monitoring Network Surveillance Year 2008 Principal Investigators; Centers for Disease Control and Prevention. Prevalence of autism spectrum disorders--Autism and Developmental Disabilities Monitoring Network, 14 sites, United States, 2008. MMWR Surveill Summ. 2012; 61(3):1-19.

2. Blumberg SJ, Bramlett MD, Kogan MD, Schieve LA, Jones JR, Lu MC. Changes in prevalence of parent-reported autism spectrum disorder in school-aged U.S. children: 2007 to 2011-2012. Natl Health Stat Report. 2013(65):1-11.

3. Kim YS, Leventhal BL, Koh YJ, Fombonne E, Laska E, Lim EC, et al. Prevalence of autism spectrum disorders in a total population sample. Am J Psychiatry. 2011; 168(9):904-12.

4. Lavelle TA, Weinstein MC, Newhouse JP, Munir K, Kuhlthau KA, Prosser LA. Economic burden of childhood autism spectrum disorders. Pediatrics. 2014; 133(3):e520-9.

5. Baxter AJ, Brugha TS, Erskine HE, Scheurer RW, Vos T, Scott JG. The epidemiology and global burden of autism spectrum disorders. Psychol Med. 2015; 45 (3):601-13.

6. Bercum FM, Rodgers KM, Benison AM, Smith ZZ, Taylor J, Kornreich E, et al. Maternal stress combined with terbutaline leads to comorbid autistic-like behavior and epilepsy in a rat model. J Neurosci. 2015; 35(48):15894-902.

7. Krakowiak P, Goodlin-Jones B, Hertz-Picciotto I, Croen LA Hansen RL. Sleep problems in children with autism spectrum disorders, developmental delays, and typical developpment: a population-based study. J Sleep Res. 2008; 17(2): 197-206.

8. Pellock JM. Understanding co-morbidities affecting children with epilepsy. Neurology. 2004; 62(5 Suppl 2):S17-23.

9. Sandin S, Lichtenstein P, Kuja-Halkola R, Larsson H, Hultman CM, Reichenberg A. The familial risk of autism. JAMA 2014; 311(17):1770-7.

10. Colvert E, Tick B, McEwen F, Stewart C, Curran SR, Woodhouse $E$, et al. Heritability of autism spectrum disorder in a UK population-based twin sample. JAMA Psychiatry. 2015; 72(5):415-23.

11. Ou J, Liu R, Shen Y, Xia K, Zhao J. An overview on genetic and environmental risk of autism spectrum disorder. Glob Clin Transl Res 2019; 1(1):11-21

12. Chaidez V, Hansen RL, Hertz-Picciotto I. Gastrointestinal problems in children with autism, developmental delays or typical development. J Autism Dev Disord. 2014; 44(5): 1117-27.

13. Jyonouchi H, Geng L, Ruby A, Reddy C, Zimmerman-Bier B. Evaluation of an association between gastrointestinal symptoms and cytokine production against common dietary proteins in children with autism spectrum disorders. J Pediatr. 2005; 146(5): 605 -10.

14. McElhanon BO, McCracken C, Karpen S, Sharp WG. Gastrointestinal symptoms in autism spectrum disorder: a metaanalysis. Pediatrics. 2014; 133(5): 872-83.

15. Benach JL, Li E, McGovern MM. A microbial association with autism. MBio. 2012; 3(1):e00019-12.

16. Adams JB, Johansen LJ, Powell LD, Quig D, Rubin RA. Gastrointestinal flora and gastrointestinal status in children with autism-comparisons to typical children and correlation with autism severity. BMC Gastroenterol. 2011; 11: 22

17. Maynard CL, Elson CO, Hatton RD, Weaver CT. Reciprocal interactions of the intestinal microbiota and immune system. Nature. 2012; 489(7415):231-41.

18. Tremaroli V, Backhed F. Functional interactions between the gut microbiota and host metabolism. Nature. 2012; 489(7415):242-9.

19. Braniste V, Al-Asmakh M, Kowal C, Anuar F, Abbaspour A Toth $\mathrm{M}$, et al. The gut microbiota influences blood-brain barrier permeability in mice. Sci Transl Med. 2014; 6(263): 263 ra158.

20. Strati F, Cavalieri D, Albanese D, De Felice C, Donati C, Hayek J, et al. New evidences on the altered gut microbiota in autism spectrum disorders. Microbiome. 2017; 5(1):24.

21. Williams BL, Hornig M, Parekh T, Lipkin WI. Application of novel PCR-based methods for detection, quantitation, and phylogenetic characterization of Sutterella species in intestinal biopsy samples from children with autism and gastrointestinal disturbances. MBio. 2012; 3(1): e00261-11.

22. Williams BL, Hornig M, Buie T, Bauman ML, Cho Paik M, Wick I, et al. Impaired carbohydrate digestion and transport and mucosal dysbiosis in the intestines of children with autism and gastrointestinal disturbances. PLoS One. 2011; 6(9):e24585.

23. Kang DW, Park JG, Ilhan ZE, Wallstrom G, Labaer J, Adams JB, et al. Reduced incidence of Prevotella and other fermenters in intestinal microflora of autistic children. PLoS One. 2013; 8(7):e68322.

24. Yap IK, Angley M, Veselkov KA, Holmes E, Lindon JC, Nicholson JK. Urinary metabolic phenotyping differentiates children with autism from their unaffected siblings and age-matched controls. J Proteome Res. 2010; 9(6): 2996-3004.

25. Wang H, Liang S, Wang M, Gao J, Sun C, Wang J, et al. Potential serum biomarkers from a metabolomics study of autism. J Psychiatry Neurosci. 2016; 41(1):27-37.

26. Gabriele S, Sacco R, Cerullo S, Neri C, Urbani A, Tripi G, et al. Urinary p-cresol is elevated in young French children with autism spectrum disorder: a replication study. Biomarkers. 2014; 19(6):463-70.

27. Matsumoto M, Kibe R, Ooga T, Aiba Y, Kurihara S, Sawaki E, et al. Impact of intestinal microbiota on intestinal luminal metabolome. Sci Rep. 2012; 2:233.

28. Wikoff WR, Anfora AT, Liu J, Schultz PG, Lesley SA, Peters EC, et al. Metabolomics analysis reveals large effects of gut microflora on mammalian blood metabolites. Proc Natl Acad Sci U S A. 2009; 106(10): 3698-703.

29. Perry RJ, Peng L, Barry NA, Cline GW, Zhang D, Cardone RL, et al. Acetate mediates a microbiome-brain-beta-cell axis to promote metabolic syndrome. Nature. 2016; 534(7606): 213-7

30. Zhang C, Zhang M, Wang S, Han R, Cao Y, Hua W, et al. Interactions between gut microbiota, host genetics and diet relevant to development of metabolic syndromes in mice. ISME J. 2010; 4(2):232-41.

31. Org E, Parks BW, Joo JW, Emert B, Schwartzman W, Kang EY, et al. Genetic and environmental control of host-gut microbiota interactions. Genome Res. 2015; 25(10):1558-69.

32. Everard A, Belzer C, Geurts L, Ouwerkerk JP, Druart C, Bindels LB, et al. Cross-talk between Akkermansia muciniphila and intestinal epithelium controls diet-induced obesity. Proc Natl Acad Sci U S A. 2013; 110 (22):9066-71.

33. Hsiao EY, McBride SW, Hsien S, Sharon G, Hyde ER, McCue $\mathrm{T}$, et al. Microbiota modulate behavioral and physiological abnormalities associated with neurodevelopmental disorders. Cell. 2013; 155(7):1451-63.

34. Brown AS, Sourander A, Hinkka-Yli-Salomaki S, McKeague IW, Sundvall J, Surcel HM. Elevated maternal C-reactive protein and autism in a national birth cohort. Mol Psychiatry. 2014; 19(2):259-64.

35. Estes ML, McAllister AK. Immune mediators in the brain and peripheral tissues in autism spectrum disorder. Nat Rev Neurosci. 2015; 16(8):469-86.

36. McDougle CJ, Landino SM, Vahabzadeh A, O'Rourke J, Zurcher NR, Finger BC, et al. Toward an immune-mediated subtype of autism spectrum disorder. Brain Res. 2015; 1617:72-92. 
37. Patterson PH. Immune involvement in schizophrenia and autism: etiology, pathology and animal models. Behav Brain Res. 2009; 204(2):313-21.

38. Estes ML, McAllister AK. Maternal immune activation: Implications for neuropsychiatric disorders. Science. 2016; 353(6301):772-7.

39. Vargas DL, Nascimbene C, Krishnan C, Zimmerman AW, Pardo CA. Neuroglial activation and neuroinflammation in the brain of patients with autism. Ann Neurol. 2005; 57(1): 67-81.

40. Masi A, Quintana DS, Glozier N, Lloyd AR, Hickie IB, Guastella AJ. Cytokine aberrations in autism spectrum disorder: a systematic review and meta-analysis. Mol Psychiatry. 2015; 20(4):440-6.

41. El-Ansary A, Al-Ayadhi L. GABAergic/glutamatergic imbalance relative to excessive neuroinflammation in autism spectrum disorders. J Neuroinflammation. 2014; 11:189.

42. Xu N, Li X, Zhong Y. Inflammatory cytokines: potential biomarkers of immunologic dysfunction in autism spectrum disorders. Mediators Inflamm. 2015; 2015:531518.

43. Goines PE, Croen LA, Braunschweig D, Yoshida CK, Grether J, Hansen R, et al. Increased midgestational IFN-gamma, IL4 and IL-5 in women bearing a child with autism: A casecontrol study. Molecular Autism. 2011; 2:13.

44. Thaiss CA, Zmora N, Levy M, Elinav E. The microbiome and innate immunity. Nature. 2016; 535 (7610):65-74.

45. Hsiao EY, McBride SW, Chow J, Mazmanian SK, Patterson $\mathrm{PH}$. Modeling an autism risk factor in mice leads to permanent immune dysregulation. Proc Natl Acad Sci U S A. 2012; 109(31):12776-81.

46. Malkova NV, Yu CZ, Hsiao EY, Moore MJ, Patterson PH. Maternal immune activation yields offspring displaying mouse versions of the three core symptoms of autism. Brain Behav Immun. 2012; 26(4):607-16.

47. Shin Yim Y, Park A, Berrios J, Lafourcade M, Pascual LM, Soares N, et al. Reversing behavioral abnormalities in mice exposed to maternal inflammation. Nature. 2017; 549 (7673):482-7.

48. Wu HJ, Ivanov, II, Darce J, Hattori K, Shima T, Umesaki Y, et al. Gut-residing segmented filamenttous bacteria drive autoimmune arthritis via T helper 17 cells. Immunity.2010; 32(6):815-27.

49. Kim S, Kim H, Yim YS, Ha S, Atarashi K, Tan TG, et al. Maternal gut bacteria promote neurodevelopmental abnormalities in mouse offspring. Nature. 2017; 549 (7673):528-32.

50. Round JL, Lee SM, Li J, Tran G, Jabri B, Chatila TA, et al. The Toll-like receptor 2 pathway establishes colonization by a commensal of the human microbiota. Science. 2011; 332 (6032):974-7.

51. Ivanov, II, Frutos Rde L, Manel N, Yoshinaga K, Rifkin DB, Sartor RB, and et al. Specific microbiota direct the differentiation of IL-17-producing T-helper cells in the mucosa of the small intestine. Cell Host Microbe.2008; 4(4):337-49.

52. Courchesne E, Mouton PR, Calhoun ME, Semendeferi K, Ahrens-Barbeau C, Hallet MJ, et al. Neuron number and size in prefrontal cortex of children with autism. JAMA. 2011; 306(18):2001-10.

53. Hazlett HC, Gu H, Munsell BC, Kim SH, Styner M, Wolff JJ, et al. Early brain development in infants at high risk for autism spectrum disorder. Nature. 2017; 542(7641):348-51.

54. Le Belle JE, Sperry J, Ngo A, Ghochani Y, Laks DR, LopezAranda M, et al. Maternal inflammation contributes to brain overgrowth and autism-associated behaviors through altered redox signaling in stem and progenitor cells. Stem Cell Reports. 2014; 3(5):725-34.

55. Oskvig DB, Elkahloun AG, Johnson KR, Phillips TM, Herkenham M. Maternal immune activation by LPS selectively alters specific gene expression profiles of interneuron migration and oxidative stress in the fetus without triggering a fetal immune response. Brain Behav Immun. 2012; 26(4): 623-34.

56. Ogbonnaya ES, Clarke G, Shanahan F, Dinan TG, Cryan JF, O'Leary OF. Adult Hippocampal Neurogenesis is regulated by the microbiome. Biol Psychiatry. 2015; 78(4):e7-9.

57. Edmonson C, Ziats MN, Rennert OM. Altered glial marker expression in autistic post-mortem prefrontal cortex and cerebellum. Molecular Autism. 2014; 5(1):3.

58. Suzuki K, Sugihara G, Ouchi Y, Nakamura K, Futatsubashi $\mathrm{M}$, Takebayashi $\mathrm{K}$, et al. Microglial activation in young adults with autism spectrum disorder. JAMA Psychiatry. 2013; 70(1):49-58.

59. Erny D, Hrabe de Angelis AL, Jaitin D, Wieghofer P, Staszewski O, David E, et al. Host microbiota constantly control maturation and function of microglia in the CNS. Nat Neurosci. 2015; 18(7):965-77.

60. Tochitani S, Ikeno T, Ito T, Sakurai A, Yamauchi T, Matsuzaki H. Administration of non-absorbable antibiot-ics to pregnant mice to perturb the maternal gut microbi-ota is associated with alterations in offspring behavior. PLoS One. 2016; 11 (1): e 0138293.

61. Degroote S, Hunting DJ, Baccarelli AA, Takser L. Maternal gut and fetal brain connection: increased anxiety and reduced social interactions in Wistar rat offspring following periconceptional antibiotic exposure. Prog Neuropsychopharmacol Biol Psychiatry. 2016; 71:76-82.

62. Dominguez-Bello MG, Costello EK, Contreras M, Magris M, Hidalgo G, Fierer N, and et al. Delivery mode shapes the acquisition and structure of the initial microbiota across multiple body habitats in newborns. Proc Natl Acad Sci U S A. 2010; 107 (26):11971-5.

63. Biasucci G, Benenati B, Morelli L, Bessi E, Boehm G. Cesarean delivery may affect the early biodiversity of intestinal bacteria. J Nutr. 2008; 138(9):1796S-800S.

64. Magne F, Puchi Silva A, Carvajal B, Gotteland M. The elevated rate of cesarean section and its contribution to non-communicable chronic diseases in Latin America: the growing involvement of the microbiota. Front Pediatr. 2017; 5:192.

65. Curran EA, Dalman C, Kearney PM, Kenny LC, Cryan JF, Dinan TG, et al. Association between obstetric modes of delivery and autism spectrum disorder: a population-based sibling design study. JAMA Psychiatry. 2015; 72(9):935-42.

66. Glasson EJ, Bower C, Petterson B, de Klerk N, Chaney G, Hallmayer JF. Perinatal factors and the development of autism: a population study. Arch Gen Psychiatry. 2004; 61(6):618-27.

67. Dominguez-Bello MG, De Jesus-Laboy KM, Shen N, Cox LM, Amir A, Gonzalez A, et al. Partial restoration of the microbiota of cesarean-born infants via virginal microbial transfer. Nat Med. 2016; 22(3):250-3.

68. Bronson SL, Bale TL. Prenatal stress-induced increases in placental inflammation and offspring hyperactivity are male-specific and ameliorated by maternal anti-inflammatory treatment. Endocrinology. 2014; 155(7):2635-46.

69. Jasarevic E, Howerton CL, Howard CD, Bale TL. Alterations in the vaginal microbiome by maternal stress are associated with metabolic reprogramming of the offspring gut and brain. Endocrinology. 2015; 156(9):3265-76.

70. Golubeva AV, Crampton S, Desbonnet L, Edge D, O'Sullivan $\mathrm{O}$, Lomasney KW, et al. Prenatal stress-induced alterations in major physiological systems correlate with gut microbiota composition in adulthood. Psychoneuroendocrinology. 2015; 60:58-74.

71. Lee BK, Magnusson C, Gardner RM, Blomstrom A, Newschaffer CJ, Burstyn I, et al. Maternal hospitalization with infection during pregnancy and risk of autism spectrum disorders. Brain Behav Immun. 2015; 44:100-5. 
72. Jiang HY, Xu LL, Shao L, Xia RM, Yu ZH, Ling ZX, et al. Maternal infection during pregnancy and risk of autism spectrum disorders: A systematic review and meta-analysis. Brain Behav Immun. 2016; 58: 165-72.

73. de Theije CG, Wopereis H, Ramadan M, van Eijndthoven T, Lambert J, Knol J, et al. Altered gut microbiota and activity in a murine model of autism spectrum disorders. Brain Behav Immun. 2014; 37:197-206.

74. Pearson BL, Simon JM, McCoy ES, Salazar G, Fragola G, Zylka MJ. Identification of chemicals that mimic transcriptional changes associated with autism, brain aging and neurodegeneration. Nat Commun. 2016; 7:11173.

75. Tran NQV, Miyake K. Neurodevelopmental disorders and environmental toxicants: epigenetics as an underlying mechanism. Int J Genomics. 2017; 2017:7526592.

76. Singh K, Connors SL, Macklin EA, Smith KD, Fahey JW, Talalay $\mathrm{P}$, et al. Sulforaphane treatment of autism spectrum disorder (ASD). Proc Natl Acad Sci U S A. 2014; 111 (43):15550-5.

77. Accordino RE, Kidd C, Politte LC, Henry CA, McDou-gle CJ. Psychopharmacological interventions in autism spectrum disorder. Expert Opin Pharmacother. 2016; 17(7):937-52.

78. Politte LC, Henry CA, McDougle CJ. Psychopharmacological interventions in autism spectrum disorder. Harv Rev Psychiatry. 2014; 22(2):76-92.

79. Penagarikano O, Abrahams BS, Herman EI, Winden KD, Gdalyahu A, Dong H, et al. Absence of CNTNAP2 leads to epilepsy, neuronal migration abnormalities, and core autismrelated deficits. Cell. 2011; 147 (1): 235-46.

80. McDougle CJ, Stigler KA, Erickson CA, Posey DJ. Atypical antipsychotics in children and adolescents with autistic and other pervasive developmental disorders. J Clin Psychiatry. 2008; 69 Suppl 4:15-20.

81. McDougle CJ, Scahill L, McCracken JT, Aman MG, Tierney E, Arnold LE, et al. Research units on pediatric psychopharmacology (RUPP) autism network. Background and rationale for an initial controlled study of risperidone. Child Adolesc Psychiatr Clin N Am. 2000; 9(1):201-24.

82. Urbano M, Okwara L, Manser P, Hartmann K, Herndon A Deutsch SI. A trial of D-cycloserine to treat stereotypies in older adolescents and young adults with autism spectrum disorder. Clin Neuropharmacol. 2014; 37(3):69-72.

83. Kwak MK, Kensler TW. Targeting NRF2 signaling for cancer chemoprevention. Toxicol Appl Pharmacol. 2010; 244 (1):66-76.

84. Penagarikano O, Lazaro MT, Lu XH, Gordon A, Dong H, Lam HA, et al. Exogenous and evoked oxytocin restores social behavior in the Cntnap2 mouse model of autism. Sci Transl Med. 2015; 7 (271):271ra8.

85. Guastella AJ, Hickie IB. Oxytocin treatment, circuitry, and autism: a critical review of the literature placing oxytocin into the autism context. Biol Psychiatry.2016; 79(3):23442.

86. Stoop R. Neuromodulation by oxytocin and vasopressin. Neuron. 2012; 76(1):142-59.

87. Buffington SA, Di Prisco GV, Auchtung TA, Ajami NJ, Petrosino JF, Costa-Mattioli M. Microbial reconstitution reverses maternal diet-induced social and synaptic deficits in offspring. Cell. 2016; 165(7):1762-75.

88. Rossen NG, MacDonald JK, de Vries EM, D'Haens GR, de Vos WM, Zoetendal EG, et al. Fecal microbiota transplantation as novel therapy in gastroenterology: A systematic review. World J Gastroenterol. 2015; 21(17):5359-71.

89. Li Q, Han Y, Dy ABC, Hagerman RJ. The Gut micro-biota and autism spectrum disorders. Front Cell Neurosci. 2017; 11: 120.

90. Kelly CR, Kahn S, Kashyap P, Laine L, Rubin D, Atreja A, et al. Update on fecal microbiota transplantation 2015: Indications, Methodologies, Mechanisms, and Outlook. Gastroenterology. 2015; 149(1):223-37.

91. Kang DW, Adams JB, Gregory AC, Borody T, Chittick L, Fasano A, et al. Microbiota transfer therapy alters gut ecosystem and improves gastrointestinal and autism symptoms: an open-label study. Microbiome. 2017; 5(1):10.

92. Scahill L, Jeon S, Boorin SJ, McDougle CJ, Aman MG, Dziura $J$, et al. Weight gain and metabolic consequences of risperidone in young children with autism spectrum disorder. J Am Acad Child Adolesc Psychiatry. 2016; 55(5):415-23.

93. van Nood E, Vrieze A, Nieuwdorp M, Fuentes S, Zoetendal EG, de Vos WM, et al. Duodenal infusion of donor feces for recurrent Clostridium difficile. N Engl J Med. 2013; 368 (5): 407-15.

94. Youngster I, Sauk J, Pindar C, Wilson RG, Kaplan JL, Smith $\mathrm{MB}$, et al. Fecal microbiota transplant for relapsing Clostridium difficile infection using a frozen inoculum from unrelated donors: a randomized, open-label, controlled pilot study. Clin Infect Dis. 2014; 58(11):1515-22.

95. Kelly CR, Ihunnah C, Fischer M, Khoruts A, Surawicz C, Afzali A, et al. Fecal microbiota transplant for treatment of Clostridium difficile infection in immunocompromised patients. Am J Gastroenterol. 2014; 109(7):1065-71.

96. Hourigan SK, Oliva-Hemker M. Fecal microbiota transplantation in children: a brief review. Pediatr Res. 2016; 80 (1):2-6.

How to cite this article:

Li K, Hu Z, Ou J, Xia K. Altered gut microbiome in Autism Spectrum Disorder: potential mechanism and implications for clinical intervention. Glob Clin Transl Res. 2019; 1(1):45-52.

Copyright (C) 2019 by the Global Clinical and Translational Research. 